\title{
Research on the Relationship between Enterprise Developmental Support and Turnover Intention —-The moderating role of person-job matching and professional self-management
}

\author{
Wu Xiaorong ${ }^{1}$ \\ ${ }^{1}$ Business School, Nanfang College of Sun Yat-sen University, Guangzhou, China
}

\begin{abstract}
Previous studies on the relationship between developmental support and turnover intention are inconsistent. Therefore, this article introduces person-job matching and professional self-management as the moderating variables of the relationship between the two. The study found that ability matching and professional self-management both regulate the relationship between the two. For employees whose abilities do not match, developmental support has a negative predictive effect on their turnover intention; however, developmental support is not correlated with the turnover intention of the ability-matched individuals. For individuals with high professional self-management tendencies, developmental support has little correlation with turnover intentions. For individuals with low professional self-management tendencies, developmental support will be transformed into a sense of organizational support, which negatively predicts employees' turnover intentions. Finally, person-job matching and professional self-management jointly regulate the relationship between the two. The research results of this article provide some enlightenment for the human capital investment strategy of enterprises.
\end{abstract}

\section{Introduction}

In recent years, companies have invested a lot of money, time and effort in the development of employees. Studies have found that the on-the-job training and development programs of enterprises can effectively improve the workrelated abilities and work performance of employees. Therefore, the developmental support of enterprises to employees is becoming more and more important in management practice. This importance mainly comes from two aspects:

On the one hand, individuals have increasingly strong demands for their own development. Recent career development studies have put forward a new concept of modern career. A protean career believes that a linear career will be replaced by a career dominated by individual satisfaction. Different from the traditional concept of career, variability emphasizes the process of mirco-cycles of multiple and iterative development. These microcirculations include the process of exploring, trying, establishing and controlling new abilities and competitiveness of individuals. Hall believes that professionals with changeable nature can repackage and equip their knowledge, skills and abilities to adapt to and conform to changes in the work environment in order to maintain a competitive advantage in the market. The research of Frederiksen and Kato found that the accumulation of employee human capital has a positive effect on their career success.

On the other hand, the way of human capital management has gradually attracted the attention of management practitioners. With the advent of the modern knowledge economy and the impact of economic globalization, human resource management theories in the field of management have begun to be challenged and questioned. For example, when dealing with the problem of personnel mobility, traditional human resource theories seem to have no skills. Shi. Management practitioners began to look for new management theories to deal with these new management problems. "Human capital management" conformed to the needs of reality and entered the vision of practitioners. Human capital has the nature of capital, with the internal drive to take risks, pursue self-improvement, and flow to high-profit areas. As a concrete manifestation of human capital investment, the developmental support of enterprises will effectively increase the human capital stock of enterprise employees.

However, some studies on human capital investment believe that considering the risk of employee resignation, human capital investment should be cautious. At the same time, the concept of a modern career also points out that individual development goals and corporate goals will gradually separate, and employees begin to lead and manage their own careers. Therefore, should companies vigorously carry out projects to support employee

e-mail: 378727586@qq.com 
development, or should they make prudent investments in consideration of the risks brought by employee turnover? This problem needs to be solved urgently in management practice.

This article believes that if we need to clarify this issue, we should consider the relationship between the company's developmental support and the employee's intention to leave. Prior to this, the relationship between the two was mainly explained through the theory of social exchange. The theory of social exchange believes that when individuals perceive the developmental investment of an enterprise, they will adopt the principle of reciprocity and choose to stay in the enterprise more. However, Kraimer reviewed related studies and found that previous research results on the relationship between developmental support and employee turnover intention are very inconsistent, and empirical studies do not all support the interpretation of social exchange theory. Therefore, they believe that there must be some undiscovered moderating variables between developmental support and employee turnover intentions.

From the perspective of individual differences, this article believes that there are two variables that affect the relationship between developmental support and employee turnover intention: one is the situation of individual person-job matching. The second is the tendency of individual professional self-management. Therefore, this article explores the role of individual person-job matching and occupational self-management tendency to further explore the role of enterprise developmental support in management practice, in order to provide some empirical support and guidance for human capital investment decisions.

\section{Literature and assumptions}

\subsection{Selecting a Template}

First, the sense of organizational support mainly considers the company's support for employees from two aspects, one is fair assessment, and the other is the support of the boss. Research in my country has found that the sense of organizational support of Chinese employees includes three dimensions: job support, employee value recognition and concern for interests. Therefore, organizational support is usually regarded as a psychological variable. Organizational support is generally considered to be through activating individuals for social exchanges and adopting the principle of reciprocity, so that more individuals stay in the enterprise.

According to the definition of Kraimer, the developmental support of an enterprise refers to the individual's overall perception of the company's development projects and related opportunities that can help employees improve their professional skills and management level. Prior to this, there was no uniform definition of enterprise development support. The developmental support of an enterprise is often specific to an actual development project of the enterprise. In the article by Kraimer, developmental support is defined as a sense of organizational support and a psychological variable. Therefore, according to the theory of social exchange, the developmental support of an enterprise also has a positive effect on employee performance and retention. Some studies have proved this hypothesis. Developmental support provides employees with information: companies believe that employees are valuable and respect their personal development. To this end, employees have adopted the principle of reciprocity. In addition, developmental support forms a higher sense of organizational support for individuals, which in turn reduces the turnover rate.

However, some studies have found that there are inconsistent results between corporate developmental support and turnover. Lee and Bruvold found that the company's development investment does not directly affect the employee's intention to leave. And the research of Ito and Brotheridge found that the employees' perceived support for the development of the boss indirectly increases the employee's intention to leave by increasing the employee's professional ability. The research of Kraimer found that when the company cannot provide employees with suitable career opportunities, the developmental support of the company will lead to higher turnover behavior of employees.

In order to further explore the relationship between developmental support and employee turnover behavior, this study believes that researchers need to distinguish the difference between developmental support and organizational support. This study believes that there are some differences between the concept of developmental support and the concept of organizational support. Developmental support cannot be regarded as just a psychological variable, but should take into account the substantial changes of the individual. Developmental support mainly refers to the company's help employees to improve their work-related capabilities, that is, the company's human capital investment in individuals. Kraimer believe that developmental support enables individuals to improve their own abilities and obtain some information that shows their self-worth, such as certificates. This shows that developmental support can effectively help employees achieve self-improvement. In other words, developmental support is directly related to the work ability of employees. This correlation makes it impossible for researchers to completely treat developmental support as a psychological variable, but needs to consider the objective changes brought about by developmental support: developmental support will objectively improve the ability of employees. Therefore, this requires researchers to consider the employee's own ability status and the individual's needs for ability development. For this reason, this paper introduces the concepts of person-job matching and professional selfmanagement as the moderator of the relationship between the two. 


\subsubsection{The moderating effect of person-job matching}

The cognition of person-job matching plays an important role in an individual's occupation. Person-job matching can be divided into two types of matching, demand-ability fit (demand-ability fit, hereinafter referred to as ability match) and demand-value fit (supplied-value fit, hereinafter referred to as demand match). Ability matching means that an individual has sufficient knowledge, abilities and skills to meet the requirements of the position. Need matching means that the job meets the individual's needs, desires or preferences.

In recent years, a large number of domestic and foreign studies have focused on the effect of person-job matching on individual turnover intentions. The study found that ability matching and demand matching can effectively predict individual turnover intentions. However, their mechanisms are not the same. When an individual experiences a mismatch in abilities, the individual will feel that their abilities cannot meet the requirements of the environment, and overall performance will decline. If the individual is in a state of low performance for a long time, the individual will produce corresponding pressure and cause the employee to have the intention of leaving.

When the individual is not yet familiar with the job business and cannot meet the competency requirements of the job, the individual is experiencing a capability mismatch at this time. At this time, the developmental investment of the company can actually help employees handle related work and improve work performance. Then, the corresponding pressure will be reduced at this time, and there will be less intention to leave. However, when the individual has been able to meet the needs of the job and has fully mastered the relevant work business, continuous developmental support will not work for this part of the staff. Therefore, this research assumes:

Hypothesis 1: The employee's ability matching situation regulates the relationship between developmental support and turnover intention. When employees are in a capacity mismatch, developmental support and turnover intention are negatively correlated; when employees are in a capacity match, the relationship between developmental support and turnover intention is not significant.

\subsubsection{The regulatory role of professional self- management}

Among them, professional behavior includes strategic investment in human capital. This kind of self-investment in human capital will continuously improve the individual's own capabilities. When the individual's professional self-management tendency is high, because the individual will invest in his own human capital, such as participating in research courses or MBA courses, or reading in his spare time, etc., the individual's capital development satisfaction does not come from the enterprise at this time. Therefore, for individuals with high professional self-management tendencies, the impact of developmental support on employees will be reduced. However, when the individual's professional selfmanagement tendency is low, the individual will not actively seek improvement in ability, but the company always cares about the development of employees. Therefore, at this time, the developmental support of the company will be transformed from the impact of changes in objective capabilities into the psychological feeling of organizational support, prompting employees to stay in the company more. Therefore, this research assumes:

Hypothesis 2: The employee's professional selfmanagement tendency regulates the relationship between developmental support and turnover intention. For employees with high professional self-management tendency, the correlation between developmental support and turnover intention is not significant; for employees with low professional self-management tendency, developmental support will be negatively correlated with turnover intention.

\subsubsection{The joint influence of ability matching and professional self-management}

This study believes that individual ability matching and professional self-management tendencies will jointly affect the impact of developmental support on turnover intentions.

For employees with low professional selfmanagement propensity, when they encounter professional difficulties, that is, when their abilities are not matched, their developmental needs for the enterprise increase. Developmental needs can effectively improve the capabilities of such employees, thereby reducing their intention to leave. As for individuals with matching capabilities, if the company continues to provide developmental support, the individual feels more of the company's care and support, and therefore will have a lower intention to leave.

However, for employees with high professional selfmanagement propensity, individuals will use self-learning methods to improve themselves when they encounter capacity mismatches. Therefore, individuals will not leave their jobs due to lack of developmental support from the company and long-term low performance. intention. As for the employees with high ability matching, the continuous developmental support will also make the individual feel the care of the enterprise, but due to their professional self-management tendency and the management of their own professional development, the individual will pay more attention to the ability caused by the developmental support Change: The developmental support of the enterprise will gradually exceed the needs of the position by the individual's ability, making the individual's experience overqualified. A large number of studies believe that high qualifications will lead to high turnover intentions. Therefore, this research assumes:

Hypothesis 3: Ability matching and career selfmanagement will jointly regulate the relationship between developmental support and turnover intention. 


\section{Method}

\subsection{Subject}

The sample of this study comes from the frontline employees of a large equipment and machinery company in Guangdong. The questionnaires of this study were distributed through the internal network of the enterprise. A total of 342 copies of the questionnaire were distributed, 320 valid questionnaires, and the questionnaire efficiency was $93 \%$. Among them, male employees accounted for $52.2 \%$, female employees accounted for $47.8 \%$, and $62.8 \%$ of employees were between $25-35$ years old. The average working time is 5.6 years. Married employees accounted for $57.1 \%$, and $55.6 \%$ of the subjects had a bachelor degree or above.

\subsection{Measuring tools}

Intention to leave. The turnover intention uses the external change intention vector scale in the career change scale compiled by the author in other studies. The scale is based on the division of occupational change dimensions, and refers to the turnover intention vector table of Derycke et al., with a topic as the general topic, "In the past 3 months, you often have the following thoughts, please answer separately". Eight types of career changes of employees were evaluated separately. The resignation intention vector table includes: (1) leaving the current company to take up a higher position in another company, (2) leaving the current company to take up a position at the same level in another company, (3) leaving the current company Companies, start from scratch in other companies, (4) leave the current company and start their own business, (5) go back to school for further studies. There are 6 types of career changes. The questionnaire is a five-point Likert rating scale, which are "never", "occasionally", "sometimes", "often" and "always".

The questionnaire is a five-point Likert-style rating scale, which is "not consistent", "not quite consistent", "uncertain", "somewhat consistent" and "conforming". In this study, the Cronbach's $\alpha$ coefficient of the scale reached 0.766 , reaching an acceptable level of reliability.

The scale has four dimensions and a total of 16 questions. The questionnaire is a five-point Likert-style rating scale, which is "not consistent", "not quite consistent", "uncertain", "somewhat consistent" and "conforming". In this study, the Cronbach's $\alpha$ coefficient of the scale reached 0.818 , reaching an acceptable level of reliability.

There are a total of 6 questions in the original scale, with a total of two dimensions, which are measured from two levels of professional skills and management capabilities. Since the Chinese translation of the three items in each dimension is the same, there will be one final topic for professional skills and management skills. The questionnaire is a five-point Likert-style rating scale, which is "not consistent", "not quite consistent", "uncertain", "somewhat consistent" and "conforming". In this study, the Cronbach's $\alpha$ coefficient of the scale reached 0.891, reaching an acceptable level of reliability. Control variables.

The control variables of this study include: changeable career attitude and boundaryless career attitude. The study found that these two variables are individuals' attitudes towards changes in career development. Therefore, they will affect the tendency of employees to change their careers, as well as their intention to leave. The questionnaire is a five-point Likert-style rating scale, which is "not consistent", "not quite consistent", "uncertain", "somewhat consistent" and "conforming". In this study, the Cronbach's $\alpha$ coefficients of the two scales were 0.816 and 0.809 , respectively, which reached an acceptable level of reliability.

Demographic variables. According to the related research on turnover intention, this article measures and controls the employee's gender, age, education level, working time, working time, and position.

\subsection{Statistics}

Using SPSS16.0, correlation analysis and regression analysis were used to test the research hypothesis.

\section{Results analysis and discussion}

\subsection{Descriptive analysis and related analysis}

\begin{tabular}{|c|c|c|c|c|c|c|c|}
\hline Variable & Mean & $\mathrm{SD}$ & 1 & 2 & 3 & 4 & 5 \\
\hline 1 Developmental support & 3.17 & 1.11 & - & & & & \\
\hline 2 Ability matching & 3.57 & 0.78 & $0.226^{* *}$ & - & & & \\
\hline $\begin{array}{l}3 \text { Professional self- } \\
\text { management }\end{array}$ & 3.25 & 0.56 & 0.103 & $0.143^{*}$ & - & & \\
\hline $\begin{array}{l}4 \text { Changeable career } \\
\text { attitude }\end{array}$ & 3.57 & 0.52 & -0.068 & $0.169^{* *}$ & $0.535^{* *}$ & - & \\
\hline $\begin{array}{l}5 \text { Unbounded career } \\
\text { attitude }\end{array}$ & 3.51 & 0.64 & -0.091 & 0.058 & $0.534^{* *}$ & $0.393^{* *}$ & - \\
\hline 6 Resignation intention & 1.92 & 0.68 & $-0.205^{* *}$ & $-0.253^{* *}$ & $0.308^{* *}$ & $0.170^{* s}$ & $0.264^{*+*}$ \\
\hline
\end{tabular}

As shown in Table 1, the analysis results show that (1) Developmental support is negatively correlated with turnover intention $(\mathrm{r}=-0.205, \mathrm{p}<0.001)$. (2) Ability matching is negatively correlated with turnover intention $(\mathrm{r}=-0.253, \mathrm{p}<0.001)$. (3) Professional self-management is positively correlated with turnover intention $(\mathrm{r}=0.308$, $\mathrm{p}<0.001$ )

\subsection{The regulating effect of ability matching}

In Hypothesis 1, this study assumes that ability matching regulates the role of developmental support and turnover intention. Therefore, this study uses a hierarchical regression method to verify the moderating effect of ability matching. In order to avoid common method deviation, regression analysis is performed after all data is centralized. In order to statistically control the common 
method deviation caused by the same data, the Harman method was used for verification, and it was found that the maximum factor explained was $18.2 \%$, which did not explain the total variation greatly (Zhou Hao and Long Lirong, 2004). Therefore, it can be considered that there is no serious common method deviation in this study. To test the hypothesis, this study adopts the following approach: In the first step of the regression analysis, this study puts the control variables, including demographic variables such as gender and age, and two control variables into the regression equation for regression analysis. In the second step, this study puts developmental support and ability matching into the regression equation of turnover intention to verify the main effect of developmental support and ability matching on turnover intention. The third step is to incorporate the product term of developmental support and ability matching into the regression equation to examine the moderating effect of ability matching. The results of multiple regression are shown in Table 2 (steps 1-3):

Table 2 Regression analysis of developmental support, ability matching, and professional self-management

\begin{tabular}{|c|c|c|c|c|c|c|}
\hline Variable & $\beta$ Step1 & $\beta$ Step2 & $\beta$ Step3 & $\beta$ Step4 & $\beta$ Step5 & $\beta$ Step6 \\
\hline Gender & -0.050 & -0.072 & -0.069 & -0.053 & -0.058 & -0.051 \\
\hline Age & -0.061 & -0.035 & -0.032 & -0.063 & -0.074 & -0.019 \\
\hline Education level & 0.047 & 0.077 & 0.074 & 0.018 & 0.018 & 0.044 \\
\hline Marital status & $-0.219^{*}$ & $-0.191^{*}$ & $-0.181^{*}$ & $-0.165^{*}$ & -0.139 & -0.151 \\
\hline Participation time & 0.121 & 0.088 & 0.096 & 0.094 & 0.106 & 0.101 \\
\hline Job time & -0.018 & -0.006 & -0.015 & 0.008 & -0.001 & 0.000 \\
\hline Changeable career attitude & 0.066 & 0.134 & 0.122 & -0.009 & 0.002 & 0.036 \\
\hline Life without boundaries & $0.190^{* *}$ & $0.170^{*}$ & 0.165 & 0.077 & 0.080 & 0.056 \\
\hline Developmental support & & -0.103 & $-0.844^{* * *}$ & $-0.203^{* *}$ & $-1.119^{s=*}$ & $-0.776^{* *}$ \\
\hline ability matching & & $-0.290^{* * *}$ & $-0.684^{* * *}$ & $0.259^{s * *}$ & -0.198 & $-0.656^{* * *}$ \\
\hline \multicolumn{7}{|l|}{ Developmental support } \\
\hline $\mathrm{x}$ Professional self- & & & $0.942^{* *}$ & & $1.116^{* 8}$ & -0.018 \\
\hline \multicolumn{7}{|l|}{ management } \\
\hline & & & & & & -0.015 \\
\hline \multicolumn{7}{|l|}{ Developmental support $x$} \\
\hline ability matching $\mathrm{x}$ & & & & & & $0.944^{*}$ \\
\hline professional self- & & & & & & \\
\hline \multicolumn{7}{|l|}{ management } \\
\hline $\mathrm{R}^{2}$ & 0.142 & 0.246 & 0.277 & 0.209 & 0.238 & 0.343 \\
\hline $\mathrm{F}$ & 4.431 & $6.904^{* * *}$ & $7.366^{* * *}$ & $5.615^{* * *}$ & $5.999^{* * *}$ & $8.409^{* * *}$ \\
\hline$\Delta \mathrm{R}^{2}$ & 0.142 & 0.104 & 0.032 & 0.067 & 0.030 & 0.066 \\
\hline $\mathrm{F}$ & 4.431 & $14.555^{* * *}$ & $9.282^{* *}$ & $9.022^{2 s *}$ & $8.341^{* *}$ & $10.499^{* * *}$ \\
\hline
\end{tabular}

Note: Gender: $0=$ male, $1=$ female; marital status: $0=$ unmarried, $1=$ married

$$
{ }^{*} \mathrm{p}<.05, * * \mathrm{p}<.01, * * * \mathrm{p}<.001
$$

Note: $* *$ means $\mathrm{p}<0.01, *$ means $\mathrm{p}<0.05 ; \mathrm{M}$ means the mean value of the variable, $\quad \mathrm{SD}$ means the variance of the variable, $\mathrm{N}=260$

As shown in Table 1, the analysis results show that (1) Developmental support is negatively correlated with turnover intention $(\mathrm{r}=-0.205, \mathrm{p}<0.001)$. (2) Ability matching is negatively correlated with turnover intention $(\mathrm{r}=-0.253, \mathrm{p}<0.001)$. (3) Professional self-management is positively correlated with turnover intention $(\mathrm{r}=0.308$, $\mathrm{p}<0.001)$

\subsection{The regulating effect of ability matching}

In Hypothesis 1, this study assumes that ability matching regulates the role of developmental support and turnover intention. Therefore, this study uses a hierarchical regression method to verify the moderating effect of ability matching. In order to avoid common method deviation, regression analysis is performed after all data is centralized. In order to statistically control the common method deviation caused by the same data, the Harman method was used for verification, and it was found that the maximum factor explained was $18.2 \%$, which did not explain the total variation greatly (Zhou Hao and Long Lirong, 2004). Therefore, it can be considered that there is no serious common method deviation in this study. To test the hypothesis, this study adopts the following approach: In the first step of the regression analysis, this study puts the control variables, including demographic variables such as gender and age, and two control variables into the regression equation for regression analysis. In the second step, this study puts developmental support and ability matching into the regression equation of turnover intention to verify the main effect of developmental support and ability matching on turnover intention. The third step is to incorporate the product term of developmental support and ability matching into the regression equation to examine the moderating effect of ability matching. The results of multiple regression are shown in Table 2 (steps 1-3): 
Table 3 Regression analysis of developmental support, ability matching, and professional self-management

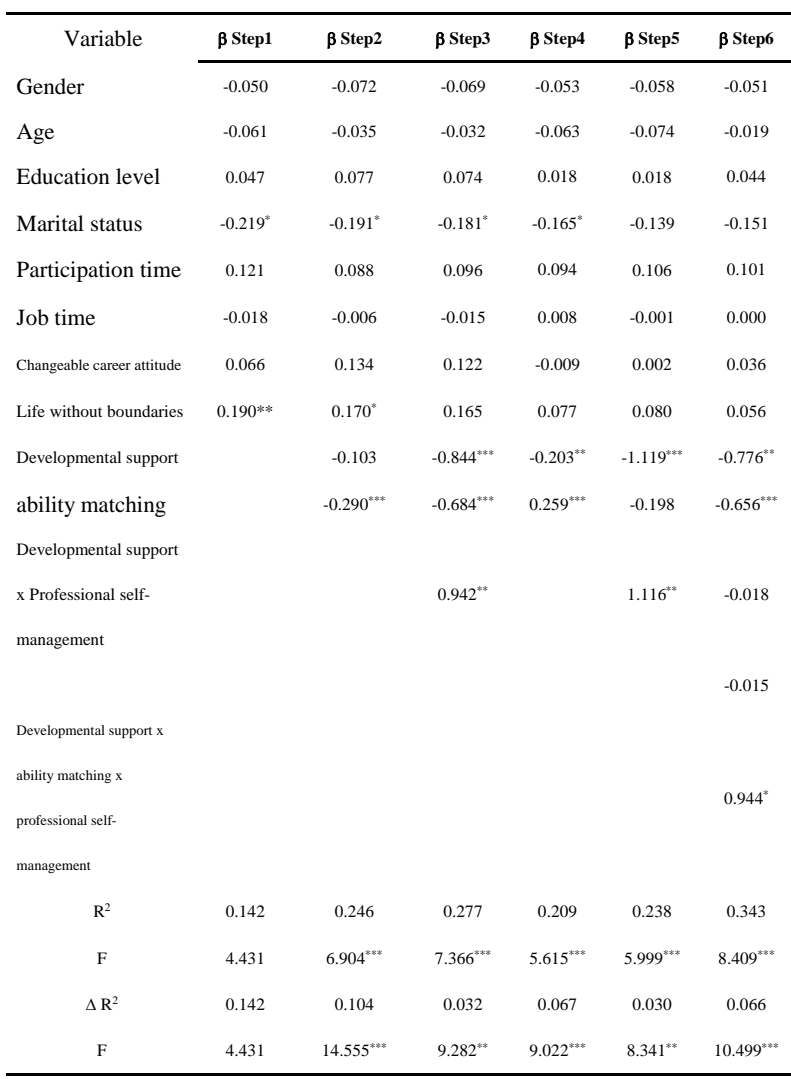

Note: Gender: $0=$ male, $1=$ female: marital status: $0=$ unmarried, $1=$ married:

$$
{ }^{*} \mathrm{p}<.05, * * \mathrm{p}<.01, * * * \mathrm{p}<.001
$$

The results of multiple regression analysis showed that when turnover intention was used as the outcome variable, as shown in Model 2 in the table above, the correlation between developmental support and turnover intention was not significant $(\mathrm{P}=0.107)$; while ability matching was negatively correlated with turnover intention $(=-0.290)$, $\mathrm{P}<0.001)$. From the results of Model 3, when the interaction term of developmental support and ability matching is included in the regression equation, the interaction product term has a significant predictive effect on turnover intention $(=0.942, \mathrm{P}<0.01 ; \Delta \mathrm{R} 2=0.032, \mathrm{~F}$ $=9.282, \mathrm{P}<0.001)$.

\section{Conclusion}

This research shows that, as a whole, the developmental support of the company can indeed effectively reduce the employee's intention to leave. However, this effect is affected by individual differences. Including the matching degree of person-job ability and professional selfmanagement tendency, they will adjust the relationship between developmental support and turnover intention.

The analysis of the results of this study shows that, for individuals whose abilities do not match, the developmental support of the enterprise can effectively reduce the employee's intention to leave. This is because the developmental support of the enterprise can effectively improve the work ability of employees and improve their work performance, so that individuals can avoid the pressure of leaving. However, these developmental supports cannot help individuals with matching abilities. This is because the individual has been able to master the abilities related to work and business, and the continuous developmental support of the company is not very helpful to the employees, so it has little effect on the intention to leave.

In addition, the results of this study show that for individuals with high professional self-management tendencies, the developmental support of the enterprise also has little effect on them. The main reason for this is that individuals with high professional self-management tendencies can effectively improve their own human capital, and it is not easy to feel excessive resignation pressure on their posts. As for individuals with low professional self-management tendencies, since they are not likely to improve themselves, the developmental support of the company serves as an external force to help individuals improve. At this time, individuals feel the company's care for their own development and are more willing to stay in the company.

More importantly, the results of this study found that the two variables of ability matching and professional self-management simultaneously affect the relationship between developmental investment and turnover intention.

For employees with high professional selfmanagement propensity, when the individual is in a capacity mismatch, the developmental support of the enterprise plays an important role in its rapid development and adapting to job requirements. Because employees with high professional self-management tend to focus on career development and pay a lot of attention to the development of their own capabilities, when they feel that their abilities do not meet the job requirements, their selfdevelopment ideas become very strong. At this time, the developmental support of the enterprise meets this demand of employees. Therefore, rapid adaptation and satisfaction of needs, both of which together make employees' intention to leave their jobs decline. However, when employees are in a state of ability matching, the continuous developmental support of the enterprise prompts more individuals to germinate the idea of leaving. This study believes that this is due to developmental support that makes individuals in a state of ability matching turn to experience over-qualification. With the improvement of individual abilities, individuals gradually find that their abilities have exceeded the requirements of the position. Accompanied by the idea of professional self-management, employees with high qualifications will feel that their value has not been fully realized, or they should go further, so they will have the intention to leave. Under such conditions, the influence of social exchange rules is covered by the needs of the covered individuals to pay attention to their own development.

Conversely, for employees with low professional selfmanagement tendencies, the developmental support of the company will play a completely different role. When the individual is in a state of ability matching, because of his low professional self-management tendency, the 
individual does not think about self-improvement and development too deliberately. At this time, the developmental support of the enterprise will transform from the actual ability improvement assistance into the perception of enterprise care. Therefore, corporate developmental support will play a role in reducing turnover intentions at this time. When the individual is in a capacity mismatch, the main function of developmental support is to help employees adapt to the requirements of the new job as soon as possible, and to improve their own abilities to get rid of long-term low performance. And this kind of help will also translate into a perception of corporate care. Therefore, developmental support will cause a greater decline in the individual's intention to leave. Under such conditions, the rules of social exchange affect the professional behavior of employees.

\section{Discussion and management inspiration}

According to the research results, in management practice, on the premise of recognizing the positive effects of enterprise developmental support, it is also necessary to recognize the inconsistency of effects brought about by individual differences. The impact of these individual differences reveals that when companies provide developmental support and invest in human capital, they need to consider both generational differences of employees and the timing of investment.

From the perspective of economic development, the new generation of knowledge workers gradually occupy the core of the labor market. Knowledge workers are often individuals with high professional self-management tendencies. When knowledge-based employees just enter the company, especially fresh graduates from universities, they will lack job-related abilities and experience in specific jobs. At this time, the developmental support of the company will enable these employees to quickly master business capabilities and gain experience. In the process of this ability improvement, developmental support can also meet the needs of knowledge employees for self-development and self-improvement. Therefore, developmental support at this stage can often keep employees in the company. With the gradual improvement of knowledge workers' abilities and more business experience, knowledge workers will reach a state of ability matching. For knowledge employees who have reached the ability match, if the company continues to provide developmental support at this time, these employees will gradually feel that their abilities exceed the needs of their positions, and they will have the idea of hopping and development. However, this does not mean that companies must stop investing in human capital. Because even if the company no longer provides training, due to the tendency of individual professional selfmanagement, it will continue to improve its own ability, and eventually the situation of over-qualification will still appear. Therefore, at this stage, the company's support for employees should be transformed into providing higher positions or more challenging jobs for employees with matching abilities or even over-qualification, so as to meet the needs of individual development and make individuals leave the state of matching. Kraimer's research is based on this situation and found that the career development opportunities provided by enterprises can regulate the relationship between developmental support and employee turnover. When the individual gets out of the match state, the developmental support of the enterprise will again play a role in retaining employees.

For the old employees who have worked in the company for a long time, based on the actual situation in our country, the professional self-management awareness of this group of employees is not very strong. With the advent of the new era and the upgrading of knowledge and skills, these employees will often be in a state of mismatch in ability. Therefore, companies should provide as much developmental support as possible at this time to help such employees improve their work performance. For older employees who can always maintain a matching ability, corresponding developmental support should also be provided to show the company's personal care for employees. Research has found that corporate care will motivate employees to create higher value, show higher organizational commitment, work performance, and more willingness to stay in the company.

\section{Acknowledgment}

Fund Project: National Natural Science Foundation of China (71072092).

\section{References}

1. Hall, D. T. Careers in and out of organizations[M]. Sage Publications, Inc, 2002

2. Frederiksen A, Kato T. Human capital and career success: evidence from linked employer-employee data[R]. Discussion paper series//Forschungsinstitut zur Zukunft der Arbeit, 2011.

3. Liu Hongying. Uncertainty, employee management model and psychological contract construction[D]. School of Management, Sun Yat-sen University, 2012.

4. Cao Weilin, Wu Xufen, Guo Jiangping. Research on the Relationship between Enterprise Training Investment Decisions and Employees' Career[J]. Chinese Journal of Management, 2007 (4): 783-787.

5. Kraimer M L, Seibert S E, Wayne S J, et al. Antecedents and outcomes of organizational support for development: The critical role of career opportunities[J]. Journal of Applied Psychology, 2011, 96(3): 485-500.

6. Ling Wenquan, Yang Haijun, Fang Liluo. Organizational Support of Enterprise Employees[J]. Journal of Psychology, 2006, 38, 281-287..

7. Benson G S, Finegold D, Mohrman S A. You paid for the skills, now keep them: Tuition reimbursement and voluntary turnover[J]. Academy of Management Journal, 2004, 47(3): 315-331. 
8. Allen D G, Shore L M, Griffeth R W. The role of perceived organizational support and supportive human resource practices in the turnover process $[\mathrm{J}]$. Journal of management, 2003, 29(1): 99-118.

9. Lee C H, Bruvold N T. Creating value for employees: investment in employee development[J]. The International Journal of Human Resource Management, 2003, 14(6): 981-1000.

10. Ito $\mathrm{J} \mathrm{K}$, Brotheridge $\mathrm{C} \mathrm{M}$. Does supporting employees' career adaptability lead to commitment, turnover, or both?[J]. Human Resource Management, 2005, 44(1): 5-19.
11. Saks A M, Ashforth B E. Is job search related to employment quality? It all depends on the fit[J]. Journal of applied Psychology, 2002, 87(4): 646-654.

12. Edwards, J. R. Person-job fit: A conceptual integration, literature review, and methodological critique[M]. // C. L. Cooper \& I. T. Robertson. International review of industrial and organizational psychology. West Sussex, England: Wiley, 1991.

13. Kristof-Brown A L, Zimmerman R D, Johnson E C. Consequences of individuals' fit at work: A metaanalysis of person-job, person-organization, persongroup, and person-supervisor fit[J]. Personnel psychology, 2005, 58(2): 281-342. 